\title{
Bovine lactoferrin free of lipopolysaccharide can induce a proinflammatory response of macrophages
}

Nada Zemankova ${ }^{1,2}$, Katarina Chlebova ${ }^{1,2}$, Jan Matiasovic ${ }^{1}$, Jana Prodelalova ${ }^{1}$, Jan Gebauer ${ }^{1,2}$ and Martin Faldyna ${ }^{1 *}$

\begin{abstract}
Background: Lactoferrin (LF) is an $80 \mathrm{kDa}$ glycoprotein which is known for its effects against bacteria, viruses and other pathogens. It also has a high potential in nutrition therapy and welfare of people and a variety of animals, including piglets. The ability to bind lipopolysaccharide (LPS) is one of the described anti-inflammatory mechanisms of LF. Previous studies suggested that cells can be stimulated even by LPS-free LF. Therefore, the aim of our study was to bring additional information about this possibility. Porcine monocyte derived macrophages (MDMF) and human embryonic kidney (HEK) cells were stimulated with unpurified LF in complex with LPS and with purified LF without bound LPS.

Results: Both cell types were stimulated with unpurified as well as purified LF. On the other hand, neither HEKO cells not expressing any TLR nor HEK4a cells transfected with TLR4 produced any pro-inflammatory cytokine transcripts after stimulation with purified LF. This suggests that purified LF without LPS stimulates cells via another receptor than TLR4. An alternative, TLR4-independent, pathway was further confirmed by analyses of the NF-kappaB-inducing kinase (NIK) activation. Western blot analyses showed NIK which activates different NFKB subunits compared to LF-LPS signaling via TLR4. Though, this confirmed an alternative pathway which is used by the purified LF free of LPS. This stimulation of MDMF led to low, but significant amounts of pro-inflammatory cytokines, which can be considered as a positive stimulation of the immune system.
\end{abstract}

Conclusion: Our results suggest that LF's ability is not only to bind LPS, but LF itself may be a stimulant of pro-inflammatory pathways.

Keywords: Inflammatory cytokines, LPS, NFKB, NIK, TLR4

\section{Background}

Lactoferrin (LF) is an $80 \mathrm{kDa}$ iron-binding glycoprotein that plays an important role in the innate immune system [1-7]. It is also a multifunctional protein with a supportive therapeutic potential against bacterial, fungal or viral infections [8-10]. At present, LF is the focus of a variety of research areas due to its anti-inflammatory and anticancer properties, and the resulting therapeutical potential [11-14]. It was found that LF interacts with LPS and then activates NFkB via TLR4 pathway [15]. This suggests that immunomodulatory effects of LF could be due, in part, to LPS binding $[16,17]$. To date, it is known that bovine LF

\footnotetext{
* Correspondence: faldyna@vri.cz

'Veterinary Research Institute, Hudcova 296/70, Brno 621 00, Czech Republic

Full list of author information is available at the end of the article
}

affects the innate immunity by activating specific events in macrophages through interaction with TLR4-dependent and TLR4-independent pathways. It was found that bovine LF function is not dependent on TLR4 with respect to IL-6 production [18]. Since LF has a broad spectrum of actions, it also uses a wide range of signaling pathways for this purpose. In addition to NFkB, LF affects also the MAP kinase pathway. There, activation of ERK1/2 as well as of p38 stress-activated kinase has been reported $[19,20]$.

NF-kappa-B-inducing kinase also known as Mitogenactivated protein kinase 14 (NIK) is encoded by the MAP3K14 gene which is a serine/threonine protein kinase [21]. NIK belongs to the group of relevant activators of the NFKB alternative pathway [22]. Although it is known that NIK is necessary for activation of the non- 
canonical pathway, it was first identified as a kinase which activates the canonical pathway downstream of TNF and IL-1 receptors. Physiological relevance of NIK in the canonical NFkB activation was examined by Zarnegar and coworkers. It was demonstrated that the role of NIK is in the amplification of signals from the canonical pathway. In concert with findings from NIK over-expression studies, NIK activates the canonical pathway when present at high levels due to stabilization [23].

LF was tested for several applications, incl. as newborn babies supplementation [24] or as a feed supplement for newborn piglets $[25,26]$. Although there are several producing systems in which LF can be produced as recombinant [27, 28], bovine colostrum still remains as an important source of bioactive constituents incl. LF [29]. Therefore, the aim of our study was to bring additional information about the pathway used by bovine LF free of LPS to stimulate porcine macrophages to the production of proinflammatory cytokines.

\section{Methods}

Preparation of MDMF from $\mathrm{CD} 14^{+}$cells

$\mathrm{CD}_{14}{ }^{+}$porcine monocytes were isolated from whole blood of six 5-6 week-old pigs as described previously [30]. Peripheral blood mononuclear cells (PBMC) were isolated from the collected whole blood by density gradient centrifugation using Histopaque-1077 (Sigma). $\mathrm{CD}_{14}{ }^{+}$monocytes were purified from PBMC by staining with mouse-anti-swine CD14 (clone MIL2, AbD Serotec, Oxford, UK, $10 \mu \mathrm{l}$ per $10^{8}$ cells) and goat-antimouse IgG MicroBeads followed by an immunomagnetic separation method (QuadroMACS ${ }^{\mathrm{TM}}$ cell separator, Miltenyi Biotec, Gladbach, Germany). The cell subset purity was assessed using flow cytometer LSRFortessa ${ }^{\mathrm{TM}}$ (BD Biosciences, San Jose, CA) and was more than $95 \%$ in all cases. Purified $\mathrm{CD}_{14}{ }^{+}$monocytes were cultured in DMEM medium supplemented with $10 \%$ fetal bovine serum and $1 \%$ antibiotics (Antibiotic Antimycotic Solution 100×: 10,000 units penicillin, $10 \mathrm{mg}$ streptomycin, and $25 \mu \mathrm{g}$ amphotericin B per mL; Sigma-Aldrich) for 4 days to differentiate into macrophages (MDMF).

\section{HEK cells preparation}

HEK 293/hTLR4A-MD2-CD14 (HEK4a) cells expressing human TLR4A, MD2 and CD14 molecules and control HEK 293/null (HEK0) cells were obtained from Invivogen (San Diego, USA). Cells were grown in DMEM (Sigma) according to the manufacturer's recommendation. The cells were seeded onto 24-well plates at the density of $2 \times 10^{5}$ cells per well. A treatment was applied as soon as the cells reached $80 \%$ confluency.

\section{Purification of lactoferrin}

In the study, bovine colostral lactoferrin (Sigma-Aldrich, USA). For part of the study, lactoferrin was purified from LPS. This method was previously described [16]. The interaction between LPS and LF was abrogated by $\mathrm{NaCl}$ concentrations higher than $0.4 \mathrm{M}$ [15]. Ten mg of LF (Sigma) was dissolved in $0.5 \mathrm{M} \mathrm{NaCl}$ of endotoxinfree water (Sigma), and centrifuged with a $100-\mathrm{kDa}$ Centricon $^{\circledR}$ Plus 70 (Millipore, Centricon, Merck KGaA) to remove endotoxin from the LF. The filtrate, an endotoxin free $\mathrm{LF}$ in $0.5 \mathrm{NaCl}$ solution, was desalted by centrifugation with the $10-\mathrm{kDa}$ Centricon ${ }^{\bullet}$ Plus 70 . The retentate was recovered, and the concentration was quantified by Pierce BCA Protein Assay Kit 23225 (Thermo Scientific). The success of the purification was estimated by Limulus Amebocyte Lysate QCL-1000 ${ }^{\text {тм }}$ (Lonza). Unpurified and purified LF contained 4.10 EU/ml and $0.05 \mathrm{EU} / \mathrm{ml}$, respectively.

\section{Iron saturation determination}

The level of iron saturation was estimated according to already described method [31]. Briefly, lactoferrin before and after LPS removal was spectroscopicaly measured at 280 and $466 \mathrm{~nm}$ with endotoxin-free water (SigmaAldrich, USA) as a blank. UV/VIS spectra were obtained using a microplate reader Synergy H1 (Biotek, USA). The acquired $\mathrm{A}_{280} / \mathrm{A}_{466}$ ratios were subsequently used to determine the iron saturation applying the correlation curve established by Majka and coworkers [31]. From accurate measurements by ELISA and ICP-mass spectrometry. The estimation of iron saturation was calculated from an equation:

$$
\begin{aligned}
\mathrm{A}_{280} / \mathrm{A}_{466} & =\mathrm{a}(\text { iron saturation })^{\mathrm{b}}, \text { where } \mathrm{a} \\
& =933.0 \pm 47, \mathrm{~b}=-0.817 \pm 0.056
\end{aligned}
$$

Iron saturation was calculated as 64 and $32 \%$ for unpurified and purified LF, respectively.

\section{Stimulation of HEK and MDMF}

In the first experiments, HEKO and HEK4a cells were treated with $100 \mu \mathrm{g} / \mathrm{ml}$ and $250 \mu \mathrm{g} / \mathrm{ml}$ of lactoferrin to prove the dose-dependent manner. In further experiments, only the dose of $100 \mu \mathrm{g} / \mathrm{ml}$ was used. This dose is sufficient for demonstrable stimulation of cells and is also appropriate because there are significant losses of starting material during purification of lactoferrin. Both types of cells were stimulated with $100 \mu \mathrm{g} / \mathrm{ml}$ unpurified or purified lactoferrin for 6 hours. After stimulation, the cells were harvested. Then, the experiment was stopped by aspiration of the medium and covering cells with RLT buffer with mercaptoethanol (for RT-PCR analysis) or Laemmli buffer (for Western blot analysis). All samples were frozen and stored at $-80{ }^{\circ} \mathrm{C}$. 


\section{Quantitative RT-PCR}

Total RNA from each well was extracted using RNeasy Mini Kit (Qiagen) according to the manufacturer's instructions. mRNA was specifically reverse-transcribed using the M-MLV reverse transcriptase system (Invitrogen, Paisley, UK) in the presence of oligo-dT primers. cDNA was diluted $5 \times$ and $0.5 \mu \mathrm{l}$ was used in qPCR. In qPCR analysis, RNA expression was quantified in triplicate reactions in a final volume of $3 \mu \mathrm{l}$ in 384-well plates using QuantiTect SYBR Green PCR master mix (Qiagen, Hilden, Germany) following the manufacturer's recommendations, on a LightCycler 480 (Roche Applied Science, http://www.roche.com/). qPCR reactions were prepared with the assistance of Nanodrop II liquid dispenser (Innovadyne Technologies, Rohnert Park, CA). qPCR was performed under the following conditions: denaturation $\left(95{ }^{\circ} \mathrm{C}\right.$ for $15 \mathrm{~min}$ ) and 45 amplification cycles $\left(95{ }^{\circ} \mathrm{C}\right.$ for $15 \mathrm{~s}, 58{ }^{\circ} \mathrm{C}$ for $30 \mathrm{~s}$ and $72{ }^{\circ} \mathrm{C}$ for $30 \mathrm{~s}$ ). The resulting melting curves were analyzed to test the product specificity. Ten pmol of each primer pair was used per reaction. Primers specific to 4 porcine and 2 human target genes and 2 porcine (HPRT, TBP-1) and 2 human (HPRT, GAPDH) reference genes were used for simultaneous measurements of gene activity (Tables 1 and 2). Among the candidate reference genes, HPRT and GAPDH in the case of MDMF and HEK, respectively, were evaluated as the most constitutively expressed genes in our samples and were selected to adjust mRNA measurements. From the obtained data, relative expression of each target gene was calculated according to the formula $[1 /(2$ target gene $\mathrm{Ct})] /[1 /(2$ reference gene $\mathrm{Ct})]$.

\section{Western blot analysis}

For Western blot analysis, MDMF protein lysates were prepared by adding lysis buffer (Cell Signaling Technology) with Laemmli buffer $(0.5 \mathrm{M}$ Tris- $\mathrm{HCl} \mathrm{pH} 6.8$, glycerol, $10 \%$ SDS, bromophenol blue, beta-mercaptoethanol, deionized water), sonicated and heated to $95{ }^{\circ} \mathrm{C}$ for $5 \mathrm{~min}$.

Table 1 Porcine primers used in the study

\begin{tabular}{lll}
\hline Gene & Sequence 5'-3' & Reference \\
\hline CXCL10/ & F: CCC ACA TGT TGA GAT CAT TGC & {$[55]$} \\
IP10 & R: CAT CCT TAT CAG TAG TGC CG & \\
HPRT & F: GAG CTA CTG TAA TGA CCA GTC AAC G & {$[56]$} \\
& R: CCA GTC TCA ATT ATA TCT TCA ACA ATC AA & \\
IL-8 & F: TTC TGC AGC TCT TCG TGA GGC & {$[57]$} \\
& R: GGT GGA AAG GTG TGG AAT GC & \\
NFkB & F: ACG AGC AGA TGG TGA AGG AG & {$[57]$} \\
& R: TCA TGG ATG ATG GCC AAG T & \\
TNFa & F: CCC CCA GAA GGA AGA GTT TC & \\
& R: CGG GCT TAT CTG AGG TT GA
\end{tabular}

Table 2 Human primers used in the study

\begin{tabular}{lll}
\hline Gene & Sequence 5'-3' & Reference \\
\hline GAPDH & F: TCC TAG ATT ATT CTC TGA TTT GGT CGT ATT G & this study \\
& R: GAA TाT GCC ATG GGT GGA ATC ATA TTG & \\
IL-8 & F: TCC AAA CCT TTC CAC CCC AAA TTT ATC & this study \\
& R: AGC TCT CTT CCA TCA GAA AGC TाT ACA ATA A & \\
TNFa & F: CAA TGG CGT GGA GCT GAG AGA TA & this study \\
& R: CCT TGA AGA GGA CCT GGG ATG AGA T & \\
\hline
\end{tabular}

Protein lysates were resolved by $10 \%$ SDS-PAGE. After gel electrophoresis, proteins were transferred onto PVDF (polyvinylidene difluoride) membranes. The membranes were blocked in $5 \%$ low-fat dry milk for $1 \mathrm{~h}$ at room temperature and followed by incubation with primary antibodies at $4{ }^{\circ} \mathrm{C}$ overnight. Primary antibodies used for membrane probing-p-IкB (Ser 32) (Santa Cruz Biotechnology), NIK antibody (Cell Signaling Technology), anti-beta actin antibody (Abcam). Anti-beta actin served as loading control. Next day, the membranes were washed and probed with secondary antibodies for $1 \mathrm{~h}$ at room temperature, followed by a washing step. The proteins were visualized on a photographic film, using ECL Plus Western blotting detection reagents (GE Healthcare Life Sciences, UK).

\section{Statistical analysis}

Data were analysed using Statistica 12 (StatSoft). The non-parametric test for paired samples (Wilcoxon's signed-rank test) was used to detect significant differences among groups. A $p$-value of $<0.05$ was considered significant.

\section{Results}

mRNA production of CXCL-10, NFKB inhibitor, IL-8 and TNFa by MDMF after LF treatment

Results in Fig. 1a-d suggest that both purified and unpurified LF stimulated MDMF cells. In the case of unpurified LF (i.e., in a complex with LPS), the TLR4dependent signaling pathway can be expected. In the case of purified LF, the TLR4-dependent pathway can be excluded. This statement is based on results of the experiment in which a medium containing 1 picogram of LPS per milliliter was used (pure LF medium). The concentration was selected because the same residual amount of LPS was detected by the LAL test in the case of the purified form of LF. The results showed that this amount had no impact on the MDMF activation.

mRNA production of IL-8 and TNFa by HEKO and HEK4a cells after unpurified LF treatment

Activation of the TLR4-dependent pathway was further excluded in experiments using permanent cell lines 


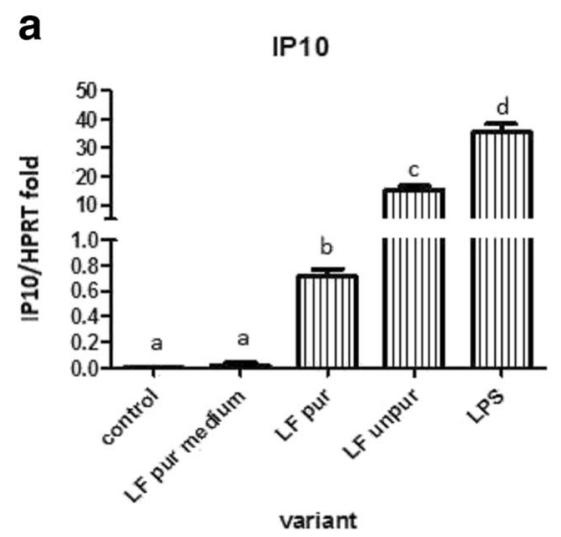

C

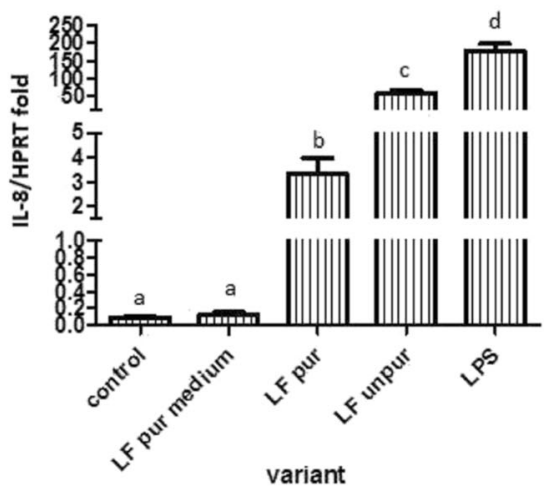

b
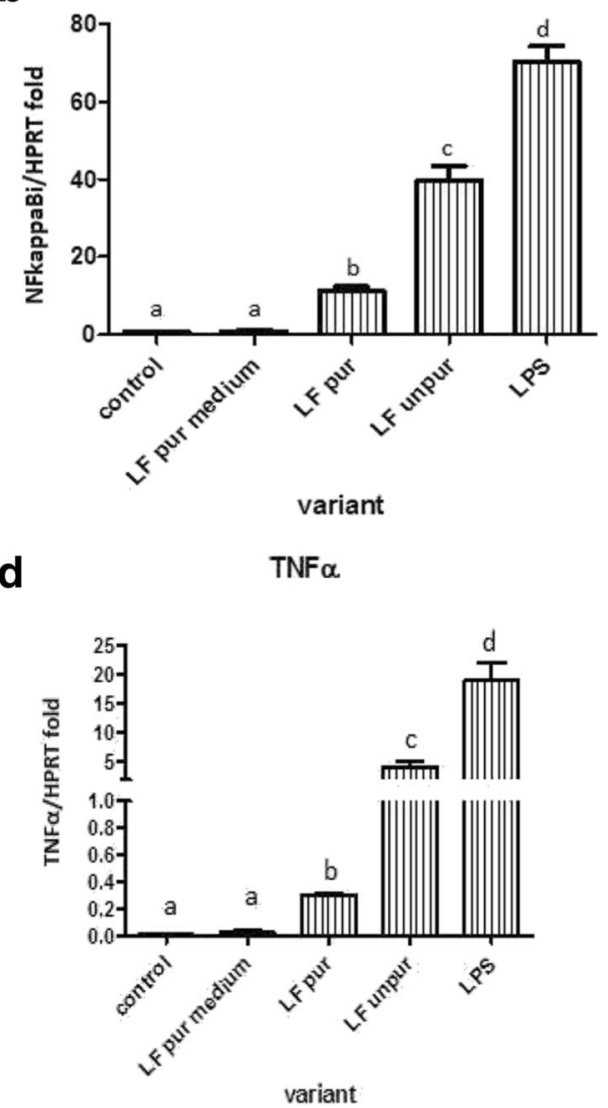

Fig. 1 Expression of mRNA for IP10 (a), NFKBi (b), IL-8 (c) and TNFa (c) by porcine monocyte-derived macrophages after stimulation with: 1 $\mu$ g/ml of lipopolysaccharide (LPS); unpurified lactoferrin (LF unpur) and purified lactoferrin (LF pur) containing 4.10 EU/ml and 0.05 EU/ml, respectively. Cells treated with medium containing $1 \mathrm{pg} / \mathrm{ml}$ of LPS (i.e. amount comparable with residual LPS-contamination of LF pur) or cultivated in LPS-free medium were used. Data are shown as mean $\pm \mathrm{SD}, n=6$. Different letters show statistical significance when compared with control ( $p<0.05)$

HEK0 and HEK4a that express either no TLR molecules or TLR4a-MD2-CD14 complex. As expected, stimulation of HEK0 with LPS or with two concentrations of unpurified LF (LF-LPS complex) did not increase expression of mRNA for TNF $\alpha$ and IL-8 (Fig. 2a, c). In the case of HEK4a, this response was induced (Fig. 2b, d).

In contrast to results shown in Fig. $2 b$ and $d$, expression of mRNA for pro-inflammatory cytokines was not increased when purified LF was used (Fig. 3a, b). The production of IL- 8 and TNF $\alpha$ was increased only in the case of unpurified LF and LPS, and it was partially decreased by Polymyxin B (PMB).

\section{Western blot}

Western blot analysis confirmed that expression of mRNA for pro-inflammatory cytokines in response to LPS alone or unpurified LF (LF-LPS) was conducted via TLR4 and NFKB pathway activation (Fig. 4). Moreover, Western blot analysis also confirmed that MDMF, when stimulated with purified LF, were activated via TLR4independent pathway. It is clear from the fact that NIK associated with activation of alternative $\mathrm{NF} \kappa \mathrm{B}$ pathway was present (Fig. 5).

\section{Discussion}

The aim of this study was to extend our knowledge about immunomodulatory properties of LF and particularly about the pathway used by LF free of LPS to stimulate macrophages to the production of proinflammatory cytokines.

As expected, MDMF responded to the stimulation with unpurified LF containing LPS by the production of proinflammatory cytokines. To a lesser extent, these cells were stimulated also by purified LPS-free LF. It suggested that this stimulation is LPS independent so does not use the TLR4 associated pathway. This was confirmed when HEK4a cells were treated with purified LPS-free LF. These cells expressing only TLR4 did not increase the production of IL-8 and TNFa transcripts when compared to control. TLR4-dependent activation was observed only in the case when these cells were stimulated with LF-LPS complex in a dose-dependent 
a

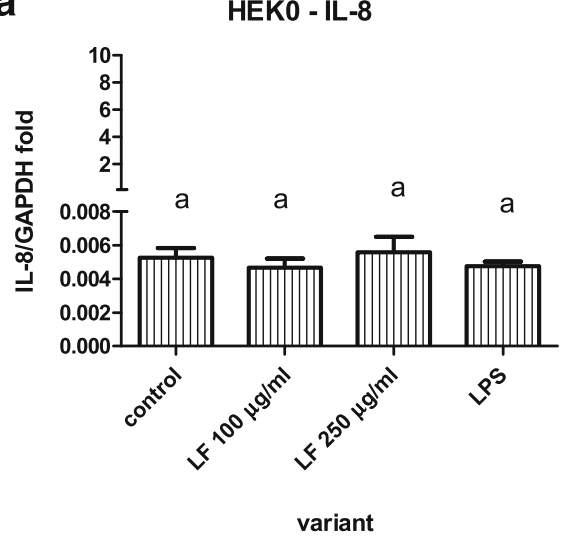

C

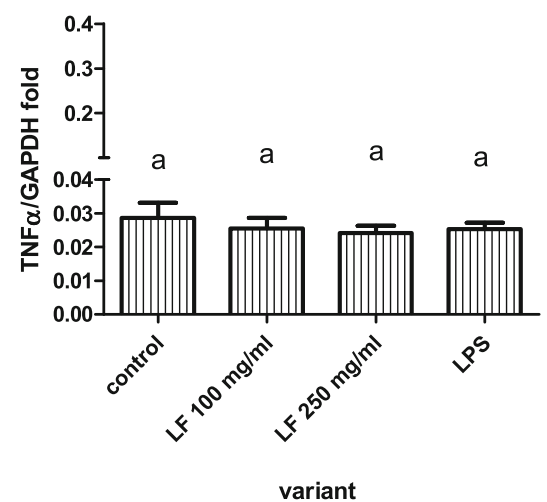

b

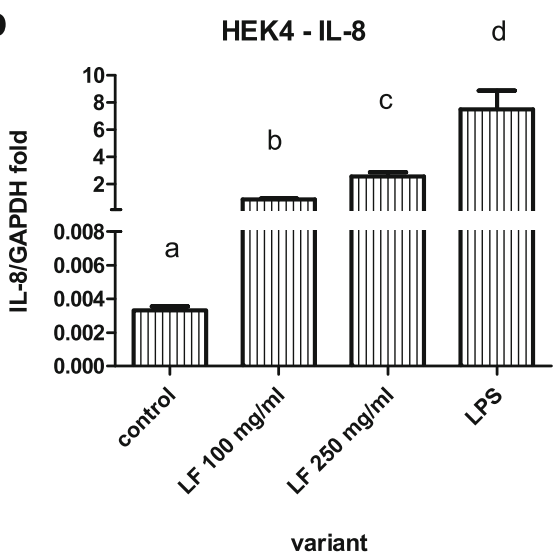

d

HEK4 - TNF $\alpha$

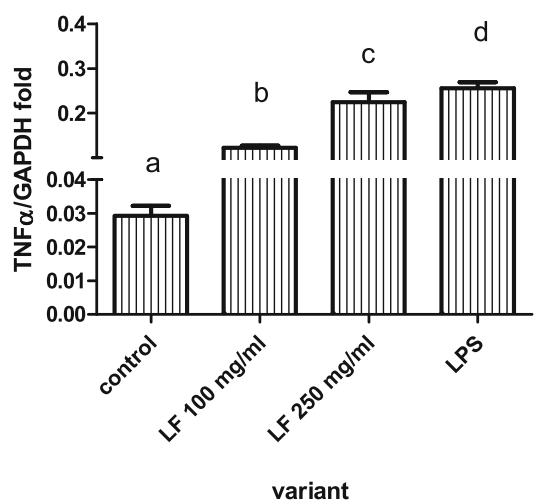

Fig. 2 Expression of mRNA for IL8 (a and $\mathbf{b})$ and TNFa (c and $\mathbf{d})$ by HEK cell line expressing no TLR ( $\mathbf{a}$ and $\mathbf{c}$ ) or the same cell line expressing TLR4a-MD2-CD14 (b and $\mathbf{d}$ ) after stimulation with two concentrations of lactoferrin (LF) or $1 \mu \mathrm{g} / \mathrm{ml}$ of lipopolysaccharide (LPS). Data are shown as mean \pm SD of 5 repetitions. Different letters show statistical significance when compared with control $(p<0.05)$

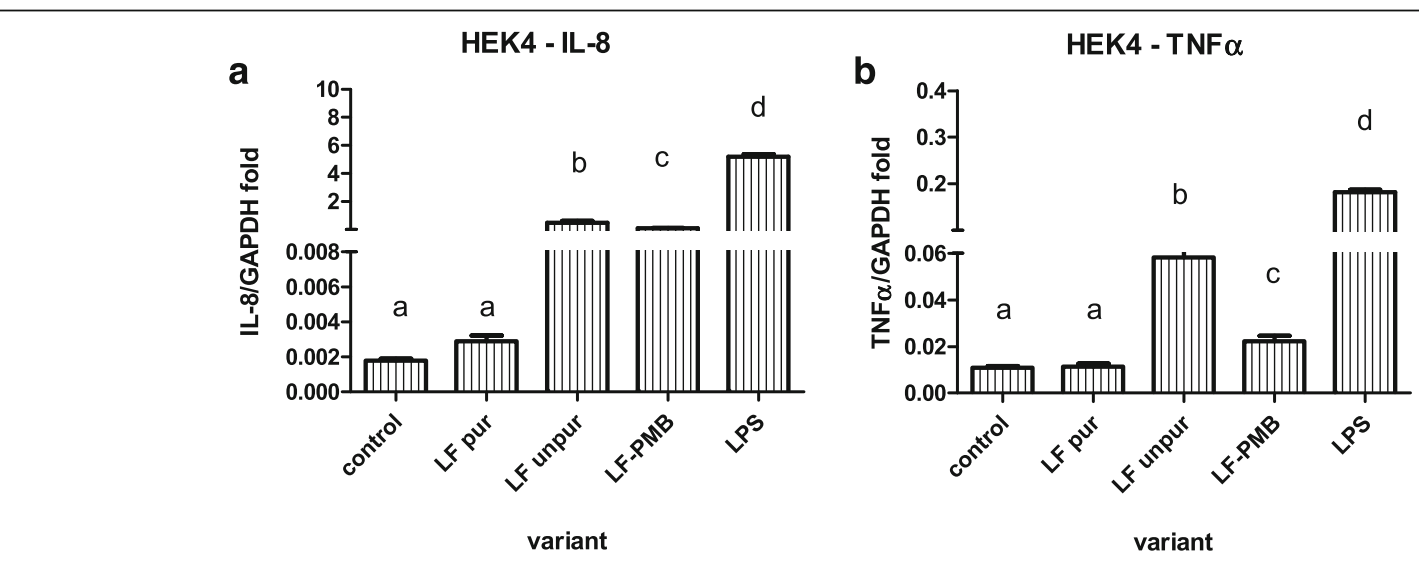

Fig. 3 Expression of mRNA for IL8 (a) and TNFa (b) by HEK cell line expressing TLR4a-MD2-CD14 after stimulation with $1 \mu \mathrm{g} / \mathrm{ml}$ of lipopolysaccharide (LPS); unpurified lactoferrin (LF unpur) and purified lactoferrin (LF pur) containing $4.10 \mathrm{EU} / \mathrm{ml}$ and $0.05 \mathrm{EU} / \mathrm{ml}$, respectively. Cells stimulated with unpurified LF in combination with polymyxine B are marked as LF-PMB. Cells cultivated in LPS-free medium were used. Data are shown as mean \pm SD of 5 repetitions. Different letters show statistical significance when compared with control $(p<0.05)$ 


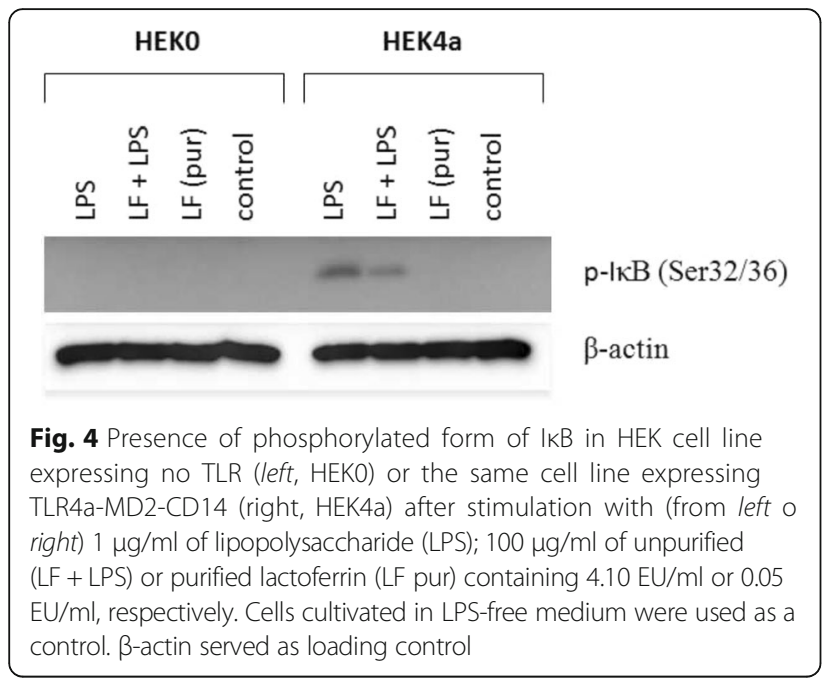

manner. This confirmed that LPS-free LF does not activate cells via TLR4 and suggested that it uses an alternative pathway. To confirm that, Western blot analyses were used. Purified LPS-free LF uses an alternative pathway which activates NIK (NF-kB-inducing kinase). NIK forms a complex with phosphorylated IKK1 and IKK2, subsequently leading to the phosphorylation of $I_{\kappa} B$ and translocation of NF- $\mathrm{KB}$ to the nucleus [32]. NIK is essential for alternative $\mathrm{NF} \kappa \mathrm{B}$ pathway, being required for the processing of p100 to p52 [22]. Concerning LPS, it is known that NIK induces phosphorylation of IKK1, that

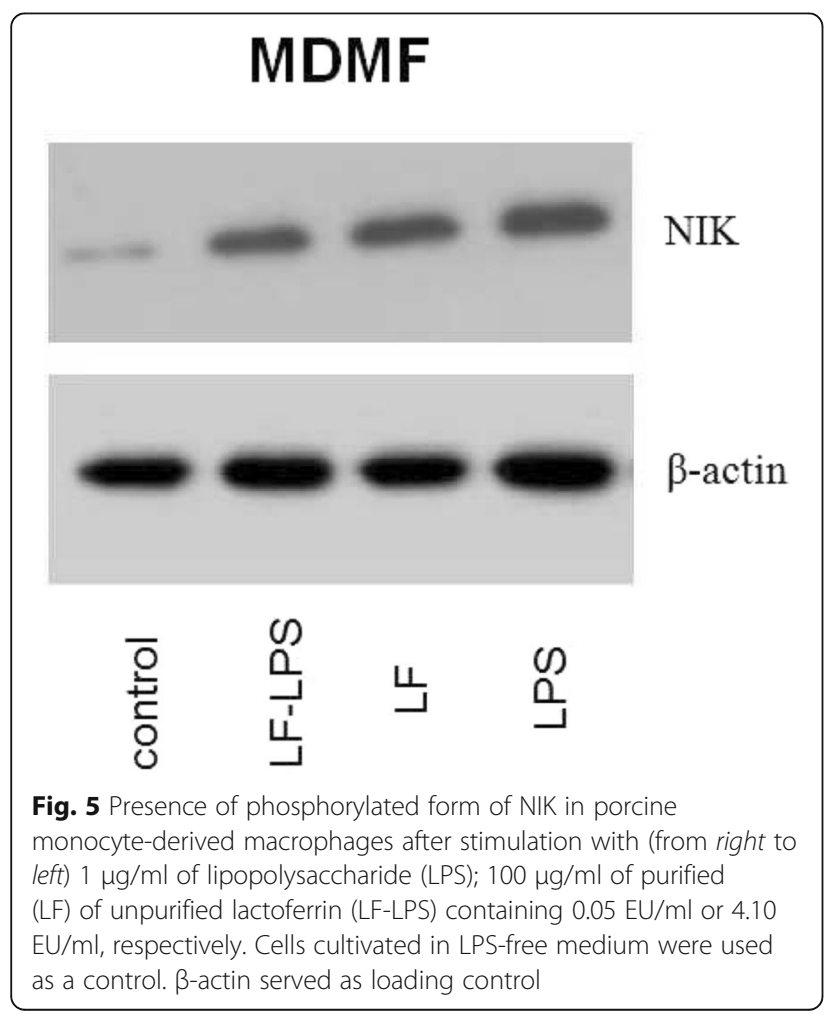

in turn phosphorylates histone $\mathrm{H} 3$ [33]. It may be relevant also for LF-LPS (unpurified LF) treatment. Zarnegar and coworkers showed the relevance of NIK in canonical NFKB pathway, when NIK is present at high levels. They demonstrated elevation of canonical NFKB pathway activity on TRAF3-/- mice. In this case NIK was stabilized and present at high levels due to the deficiency of TRAF3 [23]. TRAF3 is an essential negative regulator of alternative $N F \kappa B$ pathway, but in the study it was shown that TRAF3 suppresses canonical $N F K B$ activation and gene expression both in vitro and in vivo. Deregulation of canonical pathway in TRAF3-deficient cells causes NIK accumulation, i.e. TRAF3 inhibition results in coordinated activation of both canonical and alternative pathways [23]. NIK probably lies at a cross road of the canonical and non-canonical pathways of $\mathrm{NF \kappa B}$ and it maintains the positive and negative regulatory balance between these two pathways. Maintaining this balance is crucial for the proper physiological responses [32, 34].

LF has no specific receptor on the surface of monocytes/macrophages. It can bind to different low- or highaffinity receptors. The similar route leading to NFкB activation is conducted via RAGE (receptor for advanced glycation endproducts) which is a multiligand receptor expressed on macrophages, neurons, endothelial cells and a variety of tumor cells $[35,36]$ and TREM-1 (trigerring receptor expressed on myeloid cells 1 ) a member of the immunoglobulin superfamily which was found on monocytes and neutrophils [37]. Signals which are conducted via RAGE activate two major pathways. First one comprises CDC42/Rac and the second one encompasses MAPKs that finally lead to NFKB activation [38]. TREM1 is a positive regulator of inflammation [37]. One of the main mechanisms mediating the expression of TREM-1 is activation of NFKB [39]. TREM-1 modulates the activity and availability of key proteins of the TLR4 signaling cascade [40]. TREM-1 influences TLR4 signaling cascade positively by driving TLR4 into the lipid rafts [41]. In other words, signal conducted via TLR4, RAGE and TREM-1 use connected patways and lead to NFKB activation.

LF has the potential to modify the course of an infection [42]. Being immunomodulator, LF is used as adjunct therapeutic which can alter the immune status of the infected host. Bovine LF is widely used as therapeutic agent or food additive in many animal or human models. In the mouse model, it improves host survival modestly concurrent with the decreased serum cytokines [43] or it protects gut integrity in mouse models of LPS endotoxaemia [44]. Its immunomodulatory properties were also confirmed in the influence of low endotoxine bovine milk LF $(<0.2 \mathrm{EU} / \mathrm{mg})$ on expression of presentation molecules on bone marrow derived macrophages 
(BMMs) study. LF modulated the activity of macrophages and their ability to present an antigen and to stimulate T-cells through increased surface expression of antigen presentation and co-stimulatory molecules such as CD80 and CD86. BMMs cultured with bovine LF increased the number of $\mathrm{MHC} \mathrm{II}^{+}$cells [45].

In humans, LF is known to be able to prevent the onset of sepsis in infants [46-48]. LF has a high homology among species [49] thus, heterologous molecules of LF are used as a therapeutic agents. Although, the better protective or immunomodulatory effect of homologous recombinant LF could be expected, it was not proven, concretely in the mouse model of methicillin-resistant Staphylococcus aureus challenge. Recombinant mouse LF (rmLF) and recombinant human LF (rhLF) had a high degree of overlap to modulate inflammatory responses. Both recombinant molecules caused a decrease in inflammatory cytokine production in monocytes and an increase of cytokine production in granulocytes during the infection. But the two heterologous recombinant molecules showed some differences in their activities concerning cellular population that were used in the studies-mouse granulocytes demonstrated a different cytokine pattern upon the infection than human granulocytes. LFs were produced under endotoxin free serum conditions, and further affinity purified to remove traces of endotoxin [42]. The data show that endotoxin-free LF has not only immunomodulatory effects but also the therapeutic effects which have different essence than just LPS binding.

A similar study in which low endotoxin human milk LF $(<10 \mathrm{EU} / \mathrm{mg})$ was used supports a therapeutic significance of LF in vivo. LF treatment reduced TNF- $\alpha$ and IL-6 in serum of LPS-challenged mice during LPSinduced endotoxaemia, when it was delivered to naive mice $1 \mathrm{~h}$ prior to administration of LPS. The same molecule showed a prophylactic effect of treatment with LF $18 \mathrm{~h}$ prior to LPS-induced endotoxaemia when the production of TNF- $\alpha$ but not IL- 6 was affected [50].

\section{Conclusion}

Our results suggest that LF's ability is not only to bind LPS, but LF itself may be a stimulant of proinflammatory pathways. LF's ability to bind LPS from an environment is known very well $[16,51]$. This binding is its natural property which is used for example against bacterial infections. Due to this fact, LF often occurs in an unpurified form in a complex with LPS [18]. This kind of "contamination" resulting from one of the natural properties of LF could lead to some overvalued results. It should be considered when studying the production of cytokines or chemokines after LF treatment. Similar situations were found concerning other therapeutic proteins. When testing ovalbumin, it was found that a purified form of this protein did not activate endothelial cells in vitro. If an unpurified commercial ovalbumin containing LPS was used, endothelial cells were activated in early stages of inflammation [52]. False pro-inflammatory effects of commercial alphalactalbumin were previously described in RAW 264.7 macrophages due to endotoxin contamination [53]. And, finally, other authors mentioned contamination of commercial LF [18, 54]. This fact should be borne in mind when we perform experiments in which we study proinflammatory parameters.

\section{Abbreviations \\ HEK: Human embryonic kidney; IL: Interleukin; IkB: Inhibitor of NF-kappa-B; LF: Lactoferrin; LPS: Lipopolysaccharide; MDMF: Monocyte-derived macrophages; mRNA: Messenger ribonucleic acid; NFKB: NF-kappa-B; NIK: NF-kappa-B-inducing kinase; RT-PCR: Real-time polymerase chain reaction; TLR: Toll-like receptor; TNF: Tumor necrosis factor}

\section{Acknowledgements}

Authors would like to thank Ing. Ludmila Faldikova (Veterinary Research Institute, Brno), experienced bioscience literature language advisor, for language correction.

\section{Funding}

This study was supported by the Ministry of Agriculture of the Czech Republic (QJ1310258 and RO0516) and Ministry of Education, Youth and Sports of the Czech Republic (LO1218).

\section{Availability of data and materials}

The dataset supporting the conclusions of this article is included within the article.

\section{Authors' contributions}

NZ performed preparation of MDMF, purification of lactoferrin, GRT-PCR. KC carried out western blot analysis. JM was responsible for HEK cell preparation. JG was responsible for work with lactoferrin, incl. iron saturation determination. NZ, JP and MF conceived the study. All authors helped to draft the manuscript, read and approved the final version of the manuscript.

Competing interests

The authors declare that they have no competing interests.

\section{Consent for publication}

Not applicable.

\section{Ethics approval and consent to participate}

No animal was used in the study. Part of in vitro experiments was performed on monocytes obtained from peripheral blood of six healthy pigs which were owned by the Veterinary Research Institute. Blood samples were taken by researchers with veterinary education for the scientific study. It was approved by the Branch Commission for Animal Welfare of the Ministry of Agriculture of the Czech Republic (reference number MZE1703).

\section{Author details}

1Veterinary Research Institute, Hudcova 296/70, Brno 621 00, Czech Republic.

${ }^{2}$ Faculty of Science, Masaryk University, Brno, Czech Republic.

Received: 23 May 2016 Accepted: 2 November 2016

Published online: 10 November 2016

\section{References}

1. Buckett NM, Luckas MJ, Gazvani MR, Aird IA, Lewis-Jones DI. Seminal plasma lactoferrin concentrations in normal and abnormal semen samples. J Androl. 1997;18:302-4.

2. Fullard RJ, Snyder C. Protein levels in nonstimulated and stimulated tears of normal human subjects. Invest Opthalmol Vis Sci. 1990;31:1119-26. 
3. Hayakawa T, Harada H, Noda A, Kondo T. Lactoferrin in pure pancreatic juice in chronic pancreatitis. Am J Gastroenterol. 1983;78:222-4.

4. Hetherington SV, Spitznagel JK, Quie PG. An enzyme-linked immunoassay (ELISA) for measurement of lactoferrin. J Immunol Methods. 1983;65:183-90.

5. Lonnerdal B, lyer S. Lactoferrin: Molecular structure and biological function. Annu Rev Nutr. 1995;15:93-110.

6. Ronayne De Ferre PA, Baroni A, Sambucetti ME, López NE, Ceriani Cernadas JM. Lactoferrin levels in term and preterm milk. J Am Coll Nutr. 2000;19:370-3

7. Shugars DS, Watkins CA, Cowen HJ. Salivary concentration of secretory leukocyte protease inhibitor, an antimicrobial protein, is decreased with advanced age. Gerontology. 2001;47:246-53.

8. Kondori N, Baltzer L, Dolphin GT, Mattsby-Baltzer I. Fungicidal activity of human lactoferrin-derived peptides based on the antimicrobial a $\beta$ region. Int J Antimicrob Agents. 2011;37:51-7.

9. Wakabayashi $H$, Oda $H$, Yamauchi K, Abe F. Lactoferrin for prevention of common viral infections. J Infect Chemother. 2014;20:666-71.

10. Yin C, Wong JH, Ng TB. Recent studies on the antimicrobial peptides lactoferricin and lactoferrampin. Curr Mol Med. 2014;14:1139-54.

11. Adlerova L, Bartoskova A, Faldyna M. Lactoferrin: a review. Vet Med. 2008;53:457-68.

12. Hung YP, Yang YP, Wang HC, Liao JW, Hsu WL, Chang CC, Chang SC. Bovine lactoferrin and piroxicam as an adjunct treatment for lymphocyticplasmatic gingivitis stomatitis in cats. Vet J. 2014;202:76-82.

13. Lim LY, Koh PY, Somani S, Al Robaian M, Karim R, Yean YL, Mitchell J, Tate RJ, Edrada-Ebel RA, Blatchford DR, Mullin M, Dufes C. Tumor regression following intravenous administration of lactoferrin- and lactoferricin-bearing dendriplexes. Nanomed Nanotech Biol Med. 2015;11:1445-54.

14. Zemann N, Klein P, Wetzel E, Huettinger F, Huettinger M. Lactoferrin induces growth arrest and nuclear accumulation of Smad-2 in HeLa cells. Biochimie. 2010;92:880-4

15. Van Berkel PH, Geerts ME, Van Veen HA, Mericskay M, De Boer HA, Nuijens $\mathrm{JH}$. N-terminal stretch Arg2, Arg3, Arg4and Ar g5 of human lactoferrin is essential for binding to heparin, bacterial lipopolysaccharide, human lysozyme and DNA. Biochem J. 1997;328:145-51.

16. Na YJ, Han SB, Kang JS, Yoon YD, Park SK, Kim HM, Yang KH, Joe CO. Lactoferrin works as a new LPS binding protein in inflammatory activation of macrophages. Int Immunopharmacol. 2004;4:1187-99.

17. Puddu P, Carollo MG, Belardelli F, Valenti P, Gessani S. Role of endogenous interferon and LPS in the immunomodulatory effects of bovine lactoferrin in murine peritoneal macrophages. J Leukoc Biol. 2007;82:347-53.

18. Curran CS, Demick KP, Mansfield JM. Lactoferrin activates macrophages via TLR4-dependent and -independent signaling pathways. Cell Immunol. 2006:242:23-30.

19. Oh SM, Hahm DH, Kim IH, Choi SY. Human neutrophil lactoferrin transactivates the matrixmetalloproteinase 1 gene through stress-activated MAPK signaling modules. J Biol Chem. 2001;276:42575-9.

20. Zhou Y, Zeng Z, Zhang W, Xiong W, Wu M, Tan Y, Yi W, Xiao L, Li X, Huang C, Cao L, Tang K, Li X, Shen S, Li G. Lactotransferrin: a candidate tumor suppressor-deficient expression in human nasopharyngeal carcinoma and inhibition of NPC cell proliferation by modulating the mitogen-activated protein kinase pathway. Int J Cancer. 2008;123:2065-72.

21. Malinin NL, Boldin MP, Kovalenko AV, Wallach D. MAP3K-related kinase involved in NF-kB induction by TNF, CD95 and IL-1. Nature. 1997;385:540-4.

22. Xiao G, Harhaj EV, Sun SC. NF-kappa-B-inducing kinase regulates the processing of NF-kappaB2 p100. Mol Cell. 2001;7:401-9.

23. Zarnegar B, Yamazaki S, He JQ, Cheng G. Control of canonical NF-kappaB activation through the NIK-IKK complex pathway. Proc Natl Acad Sci U S A. 2008;105:3503-8

24. Pammi M, Abrams SA. Oral lactoferrin for the prevention of sepsis and necrotizing enterocolitis in preterm infants. Cochrane Database Syst Rev. 2015;20, CD007137.

25. Nguyen DN, Li Y, Sangild PT, Bering SB, Chatterton DE. Effects of bovine lactoferrin on the immature porcine intestine. Br J Nutr. 2014;111:321-31.

26. Nguyen DN, Jiang P, Stensballe A, Bendixen E, Sangild PT, Chatterton DE. Bovine lactoferrin regulates cell survival, apoptosis and inflammation in intestinal epithelial cells and preterm pig intestine. J Proteomics. 2016;139:95-102.

27. Choi BK, Actor JK, Rios S, d'Anjou M, Stadheim TA, Warburton S, Giaccone E, Cukan M, Li H, Kull A, Sharkey N, Gollnick P, Kocięba M, Artym J, Zimecki M, Kruzel ML, Wildt S. Recombinant human lactoferrin expressed in glycoengineered Pichia pastoris: effect of terminal N-acetylneuraminic acid on in vitro secondary humoral immune response. Glycoconj J. 2008;25:581-93.

28. Hwang SA, Kruzel ML, Actor JK. CHO expressed recombinant human lactoferrin as an adjuvant for BCG. Int J Immunopathol Pharmacol. 2015;28:452-68.

29. Bagwe S, Tharappel $\amalg$, Kaur G, Buttar HS. Bovine colostrum: an emerging nutraceutical. J Complement Integr Med. 2015;12:175-85.

30. Vicenova M, Nechvatalova K, Chlebova K, Kucerova Z, Leva L, Stepanova H, Faldyna M. Anti-inflammatory activity of biologically active phospholipids endowed with anti-neoplastic potential in in vivo and in vitro porcine immune systems. BMC Complement Altern Med. 2014;1:339.

31. Majka G, Śpiewak K, Kurpiewska K, Heczko P, Stochel G, Strus M, Brindell M. A high-thoughput method for the quantification of iron saturation in lactoferrin preparations. Anal Bioanal Chem. 2013;405:5191-200.

32. Thu YM, Richmond A. NF-KB inducing kinase: A key regulator in the immune system and in cancer. Cytokine Growth Factor Rev. 2010;21:213-26.

33. Park GY, Wang X, Hu N, Pedchenko TV, Blackwell TS, Christman JV. NIK is involved in nucleosomal regulation by enhancing histone $\mathrm{H} 3$ phosphorylation by IKKalpha. J Biol Chem. 2006;281:18684-90.

34. Oeckinghouse A, Hayden MS, Gosh S. Crosstalk in NF-kB signaling pathways. Nature Immunol. 2011;12:695-708.

35. Bierhaus A, Humpert PM, Morcos M, Wendt T, Chavakis T, Arnold B, Stern DM, Nawroth PP. Understanding RAGE, the receptor for advanced glycation end products. J Mol Med. 2005:83:876-86.

36. Veloso CA, Fernandes JS, Volpe CM, Fagundes-Netto FS, Reis JS, Chaves MM, Nogueira-Machado JA. TLR4 and RAGE: similar routes leading to inflammation in type 2 diabetic patients. Diabetes Metab. 2011;37:336-42.

37. Sharif $\mathrm{O}, \mathrm{Knapp} \mathrm{S}$. From expression to signaling: roles of TREM-1 and TREM-2 in innate immunity and bacterial infection. Immunobiology. 2008;213:701-13.

38. Van Beijnum JR, Buurman WA, Griffioen AW. Convergence and amplification of toll-like receptor (TLR) and receptor for advanced glycation end products (RAGE) signaling pathways via high mobility group B1 (HMGB1). Angiogenesis. 2008;11:91-9.

39. Hosoda H, Kida S, Nagaoka I. Transcriptional regulation of mouse TREM-1 gene in RAW264.7 macrophage-like cells. Life Sci. 2011;89:115-22.

40. Arts RJW, Joosten $L A B$, van den Meer JWM, Netea MG. TREM-1: intracellular signaling pathways and interaction with pattern recognition receptors. J Leukoc Biol. 2013;93:209-15.

41. Fortin CF, Lesur O, Fulop Jr T. Effects of TREM-1 activation in human neutrophils: activation of signalling pathways, recruitment into lipid rafts and association with TLR4. Int Immunol. 2007;19:41-50.

42. Hwang SA, Kruzel ML, Actor JK. Immunomodulatory effects of recombinant lactoferrin during MRSA infection. Int Immunopharmacol. 2014;20:157-63.

43. Hwang SA, Actor JK. Lactoferrin modulation of BCG-infected dendritic cell functions. Int Immunol. 2009;21:1185-97.

44. Kruzel ML, Harari Y, Chen CY, Castro GA. Lactoferrin protects gut mucosal integrity during endotoxemia induced by lipopolysaccharide in mice. Inflammation. 2000:24:33-44.

45. Hwang SA, Kruzel ML, Actor JK. Influence of bovine lactoferrin on expression of presentation molecules on BCG-infected bone marrow derived macrophages. Biochimie. 2009;91:76-85.

46. Manzoni P, De Luca D, Stronati M, Jacqz-Aigrain E, Ruffinazzi G, Luparia M, Tavella E, Boano E, Castagnola E, Mostert M, Farina D. Prevention of nosocomial infections in neonatal intensive care units. Am J Perinatol. 2013;30:81-8

47. Ochoa TJ, Pezo A, Cruz K, Chea-Woo E, Cleary TG. Clinical studies of lactoferrin in children. Biochem Cell Biol. 2012;90:457-67.

48. Stronati M, Bollani L, Maragliano R, Ruffinazzi G, Manzoni P, Borghesi A. Neonatal sepsis: new preventive strategies. Minerva Pediatr Febbraio. 2013;65:103-10.

49. Shanbacher FL, Goodman RE, Talhouk RS. Bovine mammary lactoferrin: implications from messenger ribonucleic acid (mRNA) sequence and regulation contrary to other milk proteins. J Dairy Sci. 1992;76:3812-31.

50. Kruzel ML, Harari Y, Mailman D, Actor JK, Zimecki M. Differential effects of prophylactic, concurrent and therapeutic lactoferrin treatment on LPS-induced inflammatory responses in mice. Clin Exp Immunol. 2002;130:25-31.

51. Drago-Serrano ME, de la Garza-Amaya M, Serrano Luna J, CamposRodríguez R. Lactoferrin-lipopolysaccharide (LPS) binding as key to antibacterial and antiendotoxic effects. Int Immunopharmacol. 2012;12:1-9.

52. Watanabe J, Miyazaki Y, Zimmerman GA, Albertine KH, Mclntyre TM. Endotoxin contamination of ovalbumin suppresses murine immunologic responses and development of airway hyper-reactivity. J Biol Chem. 2003;278:42361-8 
53. Lin IC, Kuo CD. Pro-inflammatory effects of commercial alpha-lactalbumin on RAW 264.7 macrophages is due to endotoxin contamination. Food Chem Toxicol. 2010;48:2642-9.

54. Cohen MS, Rasmussen GT, Serody JS, Britigan BE. Interaction of lactoferrin and lipopolysaccharide (LPS): effects of antioxidant property of lactoferrin and the ability of LPS to prime human neutrophils for enhanced superoxide formation. J Infect Dis. 1992;166:1375-8.

55. Stepanova H, Pavlova B, Stromerova N, Ondrackova P, Stejskal K, Slana I, Zdrahal Z, Pavlik I, Faldyna M. Different immune response of pigs to Mycobacterium avium subsp. avium and Mycobacterium avium subsp. hominissuis infection. Vet Microbiol. 2012;159:343-50.

56. Zelnickova P, Matiasovic J, Pavlova B, Kudlackova H, Kovaru F, Faldyna M. Quantitative nitric oxide production by rat, bovine and porcine macrophages. Nitric Oxide. 2008;19:36-41.

57. Kyrova K, Stepanova H, Rychlik I, Faldyna M, Volf J. SPI-1 encoded genes of Salmonella Typhimurium influence differential polarization of porcine alveolar macrophages in vitro. BMC Vet Res. 2012;8:15.

58. Pavlova B, Volf J, Ondrackova P, Matiasovic J, Stepanova H, Crhanova M, Karasova D, Faldyna M, Rychlik I. SPI-1 type III secretion system of Salmonella enterica is required for the suppression of porcine alveolar macrophage cytokine expression. Vet Res. 2011;42:1.

\section{Submit your next manuscript to BioMed Central} and we will help you at every step:

- We accept pre-submission inquiries

- Our selector tool helps you to find the most relevant journal

- We provide round the clock customer support

- Convenient online submission

- Thorough peer review

- Inclusion in PubMed and all major indexing services

- Maximum visibility for your research

Submit your manuscript at www.biomedcentral.com/submit 